\title{
Singing in a silent spring: Birds respond to a half-century soundscape reversion during the COVID-19 shutdown
}

\author{
Elizabeth P. Derryberry ${ }^{1 * \dagger}$, Jennifer N. Phillips ${ }^{2,3}$, Graham E. Derryberry' ${ }^{1}$ Michael J. Blum1, David Luther ${ }^{4}$ \\ ${ }^{1}$ Department of Ecology and Evolutionary Biology, University of Tennessee, Knoxville, TN 37996, USA. ²Department of Biological Sciences, California Polytechnic State \\ University, San Luis Obispo, CA 93407, USA. ${ }^{3}$ Department of Science and Mathematics, Texas A\&M University-San Antonio, San Antonio, TX 78224, USA. ${ }^{4}$ Department of \\ Biology, George Mason University, Fairfax, VA 22030, USA. \\ *Corresponding author. Email: liz@utk.edu
}

†These authors contributed equally to this work.

Actions taken to control the coronavirus disease 2019 (COVID-19) pandemic have conspicuously reduced motor vehicle traffic, potentially alleviating auditory pressures on animals that rely on sound for survival and reproduction. Here we evaluate whether a common songbird responsively exploited newly emptied acoustic space by comparing soundscapes and songs across the San Francisco Bay Area prior to and during the recent statewide shutdown. We show that noise levels in urban areas were dramatically lower during the shutdown, characteristic of traffic in the mid-1950s. We also show that birds responded by producing higher performance songs at lower amplitudes, effectively maximizing communication distance and salience. These findings illustrate that behavioral traits can change rapidly in response to newly favorable conditions, indicating an inherent resilience to long-standing anthropogenic pressures like noise pollution.

Actions taken to mitigate the threats of coronavirus disease 2019 (COVID-19) to human life and welfare have inadvertently resulted in a natural experiment offering unanticipated insight into how human behavior affects animal behavior (1). Worldwide, elective quarantine and stay-at-home orders have reduced use of public spaces and transportation networks, especially in cities. Anecdotal media accounts suggest that restricted movement has elicited rarely observed behaviors in commensal and peri-urban animals (2). Though not all of the reports have proven to be accurate (3), widely publicized observations like coyotes crossing the normally heavily trafficked Golden Gate Bridge in the San Francisco (SF) Bay Area (California, USA) have provoked widespread fascination with the prospect that animals rapidly move back into landscapes recently vacated by humans.

Reports also indicate that animals have been exploiting newly emptied soundscapes. A number of media outlets have noted people becoming newly aware of more conspicuous animal sounds, such as bird songs, particularly in normally noisy areas (4). While people staying home may simply be paying closer attention to the animals around them, it is possible that restricted human movement reduced use of motorized vehicles, effectively unmasking bird songs otherwise obscured by associated noise pollution. Theory also suggests animals should respond to reduced background noise by altering their acoustic signals to optimize the transmission of information $(5,6)$. Resolving this uncertainty presents an unprecedented opportunity to address enduring questions about how human behavior alters soundscapes and animal acoustic behaviors (7), while offering vital insight into biotic resilience to long-standing anthropogenic pressures.

Our prior work on soundscapes and bird song across the SF Bay Area provides a strong predictive framework for testing the hypothesis that birds altered their acoustic signaling in response to reduced noise pollution during the recent statewide COVID-19 shutdown. We quantified variation in the soundscape across urban areas (San Francisco and Contra Costa County; hereafter, 'urban') and nearby, more rural areas (Marin County; hereafter, 'rural'; Fig. 1A) focusing on breeding territories of white-crowned sparrows (Zonotrichia leucophrys, Fig. 1B), a common songbird in the area (8). We also characterized songs produced by males at a subset of sites within urban and rural areas, circumscribing four independent song populations known as dialects (Fig. 1C and fig. S1). Pre-pandemic data collected in April-June of 2015 and 2016 were compared to parallel data derived from recordings made at the same sites in April-May of 2020 (i.e., shortly after execution of regional and statewide shelter-at-home mandates). To provide further context, we have drawn additional comparisons to data collected from the same urban and rural areas in prior decades, leveraging long-term studies of white-crowned sparrow song in the region (9). This approach enabled us to determine whether: (i) movement restriction resulted in a soundscape with lower anthropogenic noise levels; and whether (ii) birds responded by adjusting their communication behaviors to improve signal transmission (i.e., efficacy) and functional signal value (i.e., salience).

We have previously shown that white-crowned sparrow 
songs predictably vary according to transmission properties of urban and rural soundscapes around the SF Bay Area ( 9 , 10). While urban and rural areas both exhibit spatial variation in noise levels (10), urban soundscapes exhibit more sound energy, particularly at low frequencies, which occurs with greater traffic flow. Birds holding breeding territories in areas with higher noise levels sing higher amplitude songs (11), a common response to noise known as the Lombard effect (12). Males also produce songs with higher minimum frequencies (13) in areas with high energy, low frequency noise typical of traffic in cities (10). Consistent with signal detection theory, this improves signal efficacy by increasing communication distance (6), but it can come at a cost (14). Males that sing at higher minimum frequency often have lower vocal performance (15), which here is the ability to produce rapid trills at wide frequency bandwidths (Fig. 1, D and E) (16). Songs of males with lower vocal performance are less salient in male-male competitive interactions that occur when males defend territories $(17,18)$. Accordingly, if noise levels decline, males should produce songs at lower amplitudes (19) and lower minimum frequencies (20), thereby increasing communication distance while also allowing for higher vocal performance.

Comparison of recordings prior to and during the recent COVID-19 shutdown demonstrated that movement restriction resulted in significantly lower noise levels across more urban areas of the study region, effectively reversing more than a half-century rise in noise pollution (Fig. 2). This is well illustrated in comparisons of background noise (LAF90: the maximum noise level experienced $\geq 90 \%$ of the time), which is biologically relevant to songbirds and humans (21). Prior to the shutdown, urban white-crowned sparrow breeding territories were on average nearly three times as loud as rural territories $\left(\beta=9.2 \mathrm{~dB} \pm 2.1 ; t_{10}=4.4, p<0.002\right.$; where $9.5 \mathrm{~dB}$ is a tripling of sound pressure levels; Fig. $2 \mathrm{~A}$ and table S1). During the shutdown, background noise was dramatically lower across urban territories $\left(\beta=-7 \mathrm{~dB} \pm 0.8 ; t_{457}\right.$ $=-8.8, p<0.0001)$, but not so across rural territories $(\beta=-1.4$ $\left.\mathrm{dB} \pm 0.9 ; t_{457}=-1.6, p<0.11\right)$. This is consistent with the observation that traffic is a primary source of background noise across urban San Francisco, whereas the ocean and wind generate background noise in nearby rural Marin County (10). Notably, urban territories no longer exhibited higher noise levels than rural territories $\left(\beta=3.6 \mathrm{~dB} \pm 2.2 ; t_{10}=1.7, p<\right.$ $0.13)$. The spectral profile of noise on urban territories also converged on that of rural territories (Fig. 2B). The inference that the observed shifts are due to a reduction in the high energy, low frequency sound generated by motor vehicles is supported by traffic flow data from the Golden Gate Bridge; whereas vehicle crossings have progressively increased since the bridge opened in 1937, vehicle crossings in April-May 2020 returned to levels not seen since 1954 (Fig. 2C).
Although noise recordings are not available from the 1950s, this benchmark indicates that a relatively brief but dramatic change in human behavior effectively erased more than a half-century of urban noise pollution and concomitant soundscape divergence between urban and nearby rural areas. In other words, the COVID-19 shutdown created a proverbial silent spring across the SF Bay Area.

Movement restriction also resulted in significantly lower ambient noise levels (LAeq), which correspond to the short term, loud events occurring $\leq 10 \%$ of the time (e.g., planes flying overhead, dogs barking). Both urban and rural territories exhibited significantly lower ambient noise levels during the COVID-19 shutdown (urban: $\beta=-7.4 \mathrm{~dB} \pm 0.74 ; t_{466}=-10, p<$ 0.00001 ; rural: $\beta=-3.6 \mathrm{~dB} \pm 0.8 ; t_{466}=-4.5, p<0.00001$; fig. $\mathrm{S} 2$ and table S2). The drop in ambient noise levels in urban areas was greater than that in rural areas, again resulting in urban territory noise levels converging on those of rural territories.

We found clear evidence that birds responded to the reduction in noise pollution during the COVID-19 shutdown. Consistent with prior studies $(11,22)$, we found that birds sang more softly when noise levels were lower $(\beta=0.27 \mathrm{~dB} \pm$ $0.04 ; t_{281}=7.0, p<0.0001$, e.g., the Lombard effect) and at shorter recording distances $\left(\beta=0.43 \mathrm{~dB} / \mathrm{m} \pm 0.08 ; t_{281}=5.3\right.$, $p<0.0001$ ) before and during the shutdown. Notably, birds produced songs at even lower amplitudes during the shutdown $\left(\beta=-4.08 \mathrm{~dB} \pm 1.4 ; t_{87}=-3, p<0.004\right.$; Fig. 3, fig. S3, and table S3), well beyond what would be expected from the Lombard effect alone. This departure reveals that prevailing theories of animal communication do not capture the potential magnitude of vocal responses to noise abatement beyond the Lombard effect. Despite a reduction in song amplitude, communication distance more than doubled during the shutdown $\left(\beta=8.4 \mathrm{~dB} \pm 1.9 ; t_{87}=4.4, p<0.0001\right.$; fig. S4 and table $\mathrm{S} 4)$, further indicating the impact of noise pollution on communication during normal conditions. This doubling in communication distance could elevate fitness by reducing territorial conflicts (23) and increasing mating potential. In addition, the signal-to-noise ratio (SNR) doubled in relative energy $\left(\beta=6.5 \mathrm{~dB} \pm 2 ; t_{95}=3.3, p<0.002\right.$; table S5), which helps explain media reports suggesting that bird songs sounded louder during the shutdown (4). A doubling would allow people to hear birds at twice the previous distance, or effectively four times more birds than usual (21).

Birds also exhibited greater vocal performance in response to being released from masking by high energy, low frequency noise. We found that birds sung at lower minimum frequencies, achieving greater bandwidth songs in newly open acoustic space (Fig. 4 and tables S6 to S10). An increase in frequency bandwidth results in the transmission of more information and greater vocal performance. Greater vocal performance could also have been achieved via an increase in 
trill rate, but temporal features of song are not predicted to change with acoustic noise levels. Consistent with this prediction, we found no change in trill rate (top model $=$ null model). Observed changes in performance and related song attributes were much greater in urban than in rural areas, which corresponds to a greater decline in noise levels in urban areas. For example, songs in urban areas exhibited a 4fold greater decrease in minimum frequency $(\beta=-162 \mathrm{~Hz} \pm$ $26 ; t_{181}=-6.3, p<0.00001$; Fig. $4 \mathrm{~A}$ ) compared to songs in rural areas $\left(\beta=-40 \mathrm{~Hz} \pm 35 ; t_{181}=-1.2, p<0.26\right)$. This translated into a dramatically greater increase in vocal performance in urban songs $\left(\beta=11.1 \pm 0.6 ; t_{181}=17.3, p<0.00001\right.$; Fig. $\left.4 \mathrm{C}\right)$ compared to rural songs $\left(\beta=2.1 \pm 0.8 ; t_{181}=2.5, p<0.02\right)$. As suggested by our prior experiments $(13,15,17,18)$, the 11-point increase in vocal performance observed in urban areas far exceeds the 4-point threshold of change that results in significantly greater signal salience during male-male competition in white-crowned sparrows $(17,18)$.

Because the same individuals were not sampled at each time point (mean longevity of white-crowned sparrows is 13 months (24)), we cannot determine if the observed shift in vocal performance was due to immediate flexibility (25) or because males with higher performance (but typically more masked) songs outcompeted males with lower performance (but less masked) songs for breeding territories during the COVID-19 shutdown. It is nonetheless possible to infer that, on average, birds in urban areas exhibited significantly greater capacity to compete for breeding territories. This highlights the intriguing possibility that more juveniles preferentially copied higher performance songs during the shutdown. If so, then the shutdown may have altered the trajectory of cultural evolution within and among populations in the study region. Re-evaluating the same birds following the resumption of human activity would clarify what behavior(s) gave rise to the observed population-level shift in vocal performance and potential evolutionary outcomes of the COVID-19 shutdown.

Like the half-century soundscape reversion that occurred in more urban areas of the study region, some bird songs exhibited traits, such as trill minimum frequency, during the shutdown that have not been heard in decades (fig. S5). Comparisons of historical recordings illustrate that minimum frequencies have tracked a progressive half-century rise in background noise levels in urban songs. Notably, at the Richmond site in Contra Costa County (Fig. 1), the minimum frequency of the Berkeley dialect recorded during the COVID-19 shutdown approached lows not recorded since the spring of 1971 (Fig. 2D) (26).

Although it is well understood that noise pollution can constrain and alter animal communication $(7,19,20)$, here we show that alleviation of acoustic pressures can elicit rapid responses that increase acoustic signal efficacy and salience
(14). Our findings indicate that songbirds like white-crowned sparrows have a striking capacity to exploit newly empty soundscapes following acute but ephemeral amelioration of noise pollution, suggesting that lasting remediation might engender even more promising outcomes, such as demographic recovery and higher species diversity (27) in urban areas. Our findings illustrate that rapid recovery is possible despite long-standing legacies of chronic exposure, akin to responses that have been observed following the cessation of chemical pollution that persists in the environment (28). Determining the pace and tempo of responses to the resurgence of noise pollution following the resumption of human activity would help shed further light on behavioral resilience. It would also afford opportunities to understand broader dynamics arising from movement restriction, including the possibility that elevated threats to animal welfare lead to complex trade-offs (29). Similarly-minded assessments of organismal responses to the amelioration of other forms of pollution during the COVID-19 shutdown, like reduced $\mathrm{CO}_{2}$ emissions (30), would also provide exciting opportunities to develop a more integrated understanding of how animals respond to reduced human activity (1), including how and why animals move back into otherwise occupied landscapes and soundscapes.

\section{REFERENCES AND NOTES}

1. C. Rutz, M. C. Loretto, A. E. Bates, S. C. Davidson, C. M. Duarte, W. Jetz, M. Johnson, A. Kato, R. Kays, T. Mueller, R. B. Primack, Y. Ropert-Coudert, M. A. Tucker, M. Wikelski, F. Cagnacci, COVID-19 lockdown allows researchers to quantify the effects of human activity on wildlife. Nat. Ecol. Evol. 4, 1156-1159 (2020). doi:10.1038/s41559-020-1237-z Medline

2. S. E. Garcia, "When humans are sheltered in place, wild animals will play," New York Times, 1 April 2020;

https:/ www nytimes.com/2020/04/01/science/coronavirus-animals-wildlifegoats.html.

3. N. Daly, "Fake animal news abounds on social media as coronavirus upends life," National Geographic Magazine, 22 March 2020;

https://www.nationalgeographic.co.uk/animals/2020/03/fake-animal-newsabounds-social-media-coronavirus-upends-life.

4. D. Greene, "Do those birds sound louder to you? An ornithologist says you're just hearing things," National Public Radio, 6 May 2020; https://www.npr.org/sections/coronavirus-liveupdates/2020/05/06/843271787/do-those-birds-sound-louder-to-you-anornithologist-says-youre-just-hearing-thin.

5. J. A. Endler, Some general comments on the evolution and design of animal communication systems. Philos. Trans. R. Soc. Lond. B Biol. Sci. 340, 215-225 (1993). doi:10.1098/rstb.1993.0060 Medline

6. R. H. Wiley, "Signal detection, noise, and the evolution of communication," inAnimal Communication and Noise, H. Brumm, Ed. (Springer, 2013), vol. 2, pp. 7-30; https://doi.org/10.1007/978-3-642-41494-7_2.

7. J. P. Swaddle, C. D. Francis, J. R. Barber, C. B. Cooper, C. C. Kyba, D. M. Dominoni, G. Shannon, E. Aschehoug, S. E. Goodwin, A. Y. Kawahara, D. Luther, K. Spoelstra, M. Voss, T. Longcore, A framework to assess evolutionary responses to anthropogenic light and sound. Trends Ecol. Evol. 30, 550-560 (2015). doi:10.1016/i.tree.2015.06.009 Medline

8. Materials and methods are available as supplementary materials.

9. D. Luther, L. Baptista, Urban noise and the cultural evolution of bird songs. Proc. Biol. Sci. 277, 469-473 (2010). doi:10.1098/rspb.2009.1571 Medline

10. E. P. Derryberry, R. M. Danner, J. E. Danner, G. E. Derryberry, J. N. Phillips, S. E. Lipshutz, K. Gentry, D. A. Luther, Patterns of song across natural and anthropogenic 
soundscapes suggest that white-crowned sparrows minimize acoustic masking and maximize signal content. PLOS ONE 11, e0154456 (2016). doi:10.1371/journal.pone.0154456 Medline

11. E. P. Derryberry, K. Gentry, G. E. Derryberry, J. N. Phillips, R. M. Danner, J. E. Danner, D. A. Luther, White-crowned sparrow males show immediate flexibility in song amplitude but not in song minimum frequency in response to changes in noise levels in the field. Ecol. Evol. 7, 4991-5001 (2017). doi:10.1002/ece3.3037 Medline

12. S. A. Zollinger, H. Brumm, The Lombard effect. Curr. Biol. 21, R614-R615 (2011). doi:10.1016/j.cub.2011.06.003 Medline

13. D. A. Luther, E. P. Derryberry, Birdsongs keep pace with city life: Changes in song over time in an urban songbird affect communication. Anim. Behav. 83, 10591066 (2012). doi:10.1016/j.anbehav.2012.01.034

14. R. H. Wiley, Noise Matters: The Evolution of Communication (Harvard Univ. Press, 2015); https://doi.org/10.1016/j.anbehav.2016.04.010.

15. D. A. Luther, J. Phillips, E. P. Derryberry, Not so sexy in the city: Urban birds adjust songs to noise but compromise performance and potency in communication. Behav. Ecol. 27, 332-340 (2016). doi:10.1093/beheco/arv162

16. J. Podos, A performance constraint on the evolution of trilled vocalizations in a songbird family (Passeriformes: Emberizidae). Evolution 51, 537-551 (1997). doi:10.1111/j.1558-5646.1997.tb02441.x Medline

17. J. N. Phillips, E. P. Derryberry, Equivalent effects of bandwidth and trill rate: Support for a performance constraint as a competitive signal. Anim. Behav. 132, 209-215 (2017). doi:10.1016/j.anbehav.2017.08.012

18. J. N. Phillips, E. P. Derryberry, Vocal performance is a salient signal for male-male competition in white-crowned sparrows. The Auk 134, 564-574 (2017). doi:10.1642/AUK-17-2.1

19. H. Brumm, S. A. Zollinger, "Avian vocal production in noise," in Animal Communication and Noise, H. Brumm, Ed. (Springer, 2013), vol. 2, pp. 187-227; https://doi.org/10.1007/978-3-642-41494-7_7.

20. H. Slabbekoorn, A. den Boer-Visser, Cities change the songs of birds. Curr. Biol. 16, 2326-2331 (2006). doi:10.1016/i.cub.2006.10.008 Medline

21. R. J. Dooling, A. N. Popper, "The effects of highway noise on birds," Report prepared for the California Department of Transportation Division of Environmental Analysis (2007); https://www.researchgate.net/publication/228381219_The_Effects_of_Highwa y_Noise_on_Birds.

22. H. Brumm, The impact of environmental noise on song amplitude in a territorial bird. J. Anim. Ecol. 73, 434-440 (2004). doi:10.1111/4.0021-8790.2004.00814.x

23. J. N. Phillips, E. P. Derryberry, Urban sparrows respond to a sexually selected trait with increased aggression in noise. Sci. Rep. 8, 7505 (2018). doi:10.1038/s41598018-25834-6 Medline

24. M. C. Baker, L. R. Mewaldt, R. M. Stewart, Demography of white-crowned sparrows (Zonotrichia leucophrys nuttalli). Ecology 62, 636-644 (1981). doi:10.2307/1937731

25. G. L. Patricelli, J. L. Blickley, Avian communication in urban noise: Causes and consequences of vocal adjustment. The Auk 123, 639-649 (2006). doi:10.1093/auk/123.3.639

26. L. F. Baptista, Song Dialects and Demes in Sedentary Populations of the WhiteCrowned Sparrow (Zonotrichia leucophrys nuttalli) (Univ. of California Press, 1975).

27. L. Manzanares Mena, C. Macías Garcia, Songbird community structure changes with noise in an urban reserve. J. Urban Ecol. 4, juy022 (2018). doi:10.1093/jue/juy022

28. T. J. Mozdzer, S. E. Drew, J. S. Caplan, P. E. Weber, L. A. Deegan, Rapid recovery of carbon cycle processes after the cessation of chronic nutrient enrichment. Sci. Total Environ. 750, 140927 (2020). doi:10.1016/j.scitotenv.2020.140927Medline

29. A. E. Bates, R. B. Primack, P. Moraga, C. M. Duarte, COVID-19 pandemic and associated lockdown as a "Global Human Confinement Experiment" to investigate biodiversity conservation. Biol. Conserv. 248, 108665 (2020) doi:10.1016/i.biocon.2020.108665 Medline

30. C. Le Quéré, R. B. Jackson, M. W. Jones, A. J. P. Smith, S. Abernethy, R. M. Andrew, A. J. De-Gol, D. R. Willis, Y. Shan, J. G. Canadell, P. Friedlingstein, F. Creutzig, G. P. Peters, Temporary reduction in daily global $\mathrm{CO}_{2}$ emissions during the COVID-19 forced confinement. Nat. Clim. Chang. 10, 647-653 (2020). doi:10.1038/s41558-020-0797-x

31. J. N. Phillips, K. E. Gentry, D. A. Luther, E. P. Derryberry, Surviving in the city: Higher apparent survival for urban birds but worse condition on noisy territories. Ecosphere 9, e02440 (2018). doi:10.1002/ecs2.2440

32. J. N. Phillips, M. Berlow, E. P. Derryberry, The effects of landscape urbanization on the gut microbiome: An exploration into the gut of urban and rural white-crowned sparrows. Front. Ecol. Evol. 6, 148 (2018). doi:10.3389/fevo.2018.00148

33. P. Marler, M. Tamura, Song "dialects" in three populations of white-crowned sparrows. Condor 64, 368-377 (1962). doi:10.2307/1365545

34. E. P. Derryberry, Ecology shapes birdsong evolution: Variation in morphology and habitat explains variation in white-crowned sparrow song. Am. Nat. 174, 24-33 (2009). doi:10.1086/599298 Medline

35. E. P. Derryberry, Evolution of bird song affects signal efficacy: An experimental test using historical and current signals. Evolution 61, 1938-1945 (2007). doi:10.1111/j.1558-5646.2007.00154.x Medline

36. J. L. Blickley, G. L. Patricelli, "Potential acoustic masking of Greater Sage-Grouse (Centrocercus urophasianus) display components by chronic industrial noise," in Ornithological Monographs, no. 74 (American Ornithological Society, 2012); pp. 23-35; https://doi.org/10.1525/om.2012.74.1.23.

37. K. Marten, P. Marler, Sound transmission and its significance for animal vocalization. Behav. Ecol. Sociobiol. 2, 271-290 (1977). doi:10.1007/BF00299740

38. A. Vélez, M. D. Gall, J. Fu, J. R. Lucas, Song structure, not high-frequency song content, determines high-frequency auditory sensitivity in nine species of New World sparrows (Passeriformes: Emberizidae). Funct. Ecol. 29, 487-497 (2015). doi:10.1111/1365-2435.12352

39. J. Pinheiro, D. Bates, S. DebRoy, S. Sarkar, R Core Team, nlme: Linear and nonlinear mixed effects models. R package version 3.1-149 (2020); https://CRAN.R-project.org/package=nlme.

40. R Core Team, R: A language and environment for statistical computing ( $R$ Foundation for Statistical Computing, 2016); http://www.R-project.org/.

41. Dooling R, "Avian hearing and the avoidance of wind turbines" (National Renewable Energy Laboratory Tech. Rep. NREL/TP-500-30844, Univ. of Maryland, 2002); https://doi/org/10.2172/15000693.

42. K. Beeman, SIGNAL 5 (Engineering Design, 1999); http://www.engdes.com/index.html.

43. S. A. Zollinger, J. Podos, E. Nemeth, F. Goller, H. Brumm, On the relationship between, and measurement of, amplitude and frequency in birdsong. Anim. Behav. 84, e1-e9 (2012). doi:10.1016/j.anbehav.2012.04.026

44. B. Ballentine, The ability to perform physically challenging songs predicts age and size in male swamp sparrows, Melospiza georgiana. Anim. Behav. 77, 973-978 (2009). doi:10.1016/j.anbehav.2008.12.027

45. J. Podos, Correlated evolution of morphology and vocal signal structure in Darwin's finches. Nature 409, 185-188 (2001). doi:10.1038/35051570 Medline

46. K. Burnham, D. Anderson, Model Selection and Multimodel Inference: A Practical Information-Theoretic Approach (Springer, ed. 2, 2002); https://doi.org/10.1007/b97636.

47. H. Akaike, "Information theory and an extension of the maximum likelihood principle," in 2nd International Symposium on Information Theory, Tsahkadsor, Armenia, USSR, 2-8 September 1971, B. N. Petrov, F. Csaki, eds. (Akadémiai Kiadó, 1973); pp. 267-281.

48. R. Calaway, S. Weston, M. R. Calaway, Package 'foreach', R package version 3.3 (2017); https://cran.r-project.org/web/packages/foreach/index.html.

49. H. Wickham, J. Bryan, Package 'readxl', R package version 3.3 (2016); https://cran.r-project.org/web/packages/readxl/index.html.

50. H. Wickham, R. François, L. Henry, K. Müller, R Core Team, dplyr: A Grammar of Data Manipulation, R package version 3.3 (2020); https:/cran.r-project.org/web/packages/dplyr/index.htm.

51. Wickham H, Chang W, Henry L, Pedersen TL, Takahashi K, Wilke C, Woo K, Yutani H, Dunnington D, R Core Team, ggplot2: 955 Elegant Graphics for Data Analysis, R package version $3.3(2020)$; https://cran.r-project.org/web/packages/ggplot2/index.html.

52. M. J. Mazerolle, AICcmodavg: model selection and multimodal inference based on (Q)AIC(c), R package version 3.3 (2020);

https://cran.r-project.org/web/packages/AlCcmodavg/index.html.

\section{ACKNOWLEDGMENTS}

Work was approved by Tulane University Institutional Animal Care and Use 
Committee (IACUC protocol 0427-R) and University of Tennessee IACUC protocol 2569, Bird Banding Laboratory Permit (23900), California State Collecting Permit (6799), Golden Gate National Recreation Area (GGNRA) Scientific Research and Collecting Permit (GOGA-00079), San Francisco Parks and Recreation Permit (032014), and Point Reyes National Park (PRNS)

Scientific Research and Collecting Permit (PORE-0014). We are grateful to Mae Berlow and Leanne Norden who assisted with fieldwork, Julia Paschal who assisted with song analyses, Justin Cooper who assisted with making the map, Point Blue Palomarin Field Station staff and interns, Bill Merkle and Michael Chasse at GGNRA, Ben Becker at PRNS, Doug Bell at East Bay Regional Parks, and Lisa Wayne at San Francisco Parks and Recreation. Funding: US National Science Foundation grants 1354763, 1354756, and 1827290, NSF Postdoctoral Research Fellowship in Biology 1812280. Author contributions: EPD, JNP, MJB and DL conceived of the study; EPD, JNP and DL developed the methods and JNP collected the data; EPD and GED conducted the analyses; EPD wrote the paper with assistance of JNP, MJB and DL. The manuscript reflects the

contributions and ideas of all authors. Competing interests: None of the authors have competing interests. Data and materials availability: Data:

10.5281/zenodo.4012167. Code: $10.5281 /$ zenodo.4012143

SUPPLEMENTARY MATERIALS

science.sciencemag.org/cgi/content/full/science.abd5777/DC1

Materials and Methods

Supplementary Text

Figs. S1 to S4

Tables S1 to S10

References (31-52)

MDAR Reproducibility Checklist

29 June 2020; accepted 09 September 2020

Published online 24 September 2020

10.1126/science.abd5777 

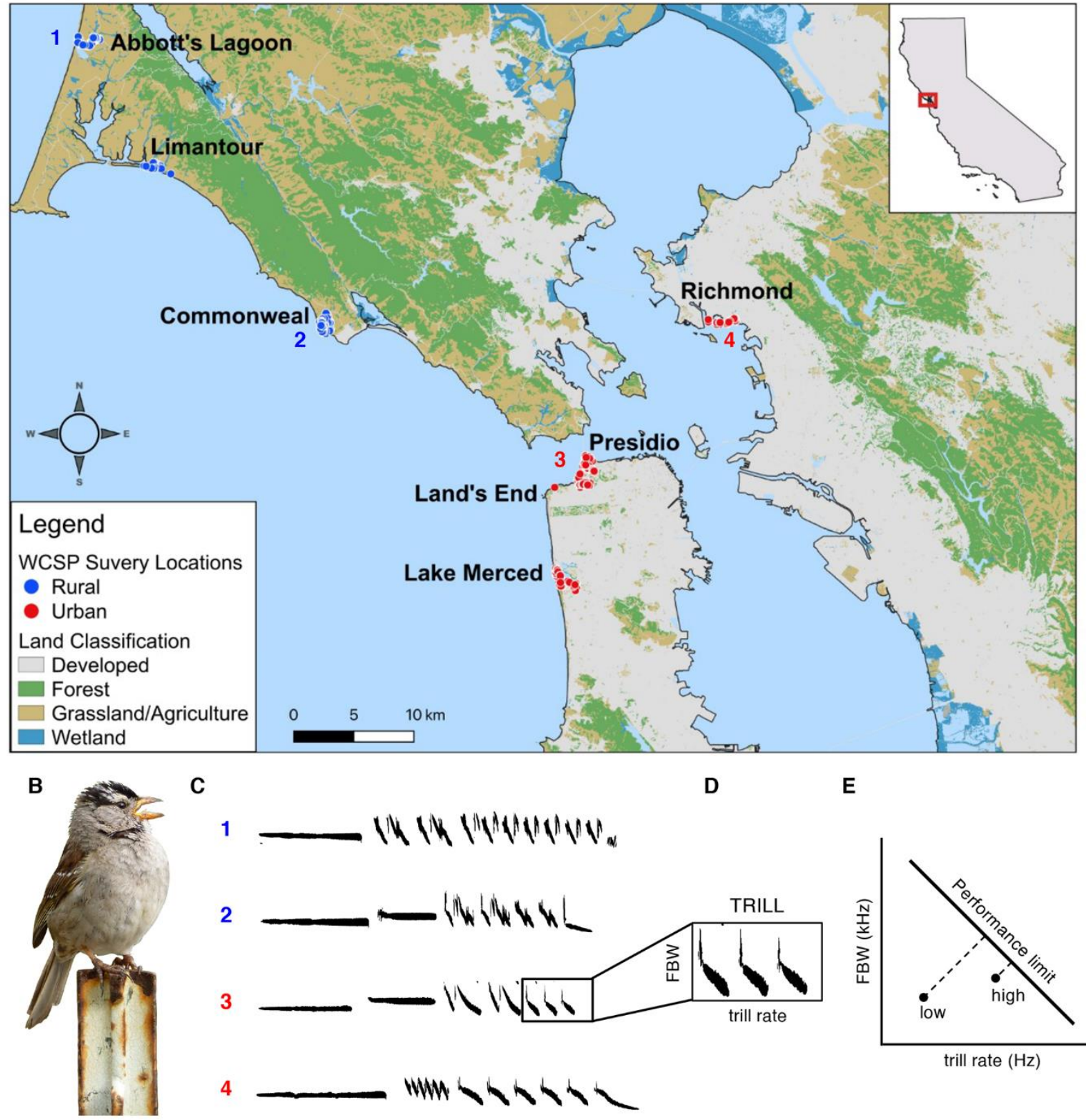

E

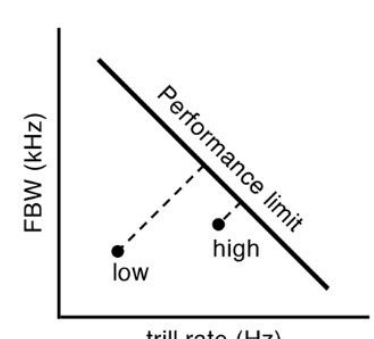

trill rate $(\mathrm{Hz})$

Fig. 1. Study system and song traits of interest. (A) Map illustrating locations where noise was recorded in urban areas (red; Presidio, Land's End and Lake Merced) of San Francisco (San Francisco Co.) and Richmond (Contra Costa Co.)) as well as in nearby, more rural areas (blue; Abbott's Lagoon, Limantour, and Commonweal (Marin Co.)) before (2016) and during (2020) the recent statewide COVID-19 shutdown. Numbers (1-4) denote locations where songs were also recorded. (B) Photograph of a male white-crowned sparrow (Zonotrichia leucophrys) singing on his territory (photo JNP). (C) Spectrograms of the four song dialects, (1) Drake, (2) Clear, (3) San Francisco, and (4) Berkeley, with numbers corresponding to their respective occurrence at sampling locations depicted in (A). Trilled portion of song boxed on San Francisco dialect to illustrate (D) measurements of trill rate (number of notes/s) and frequency bandwidth (FBW; difference between trill maximum and minimum frequency). (E) Males face a physiological limit on producing fast trills at wide frequency bandwidths, resulting in a triangular distribution of songs with an upper bound performance limit. Songs closer to the limit are denoted 'high' vocal performance as compared to songs further from the limit ('low'). 
A

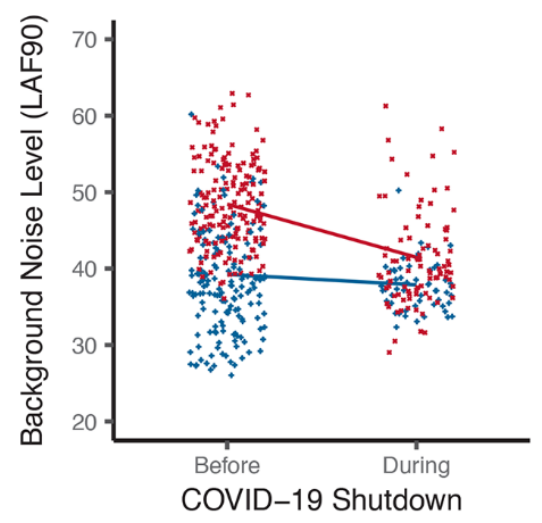

C

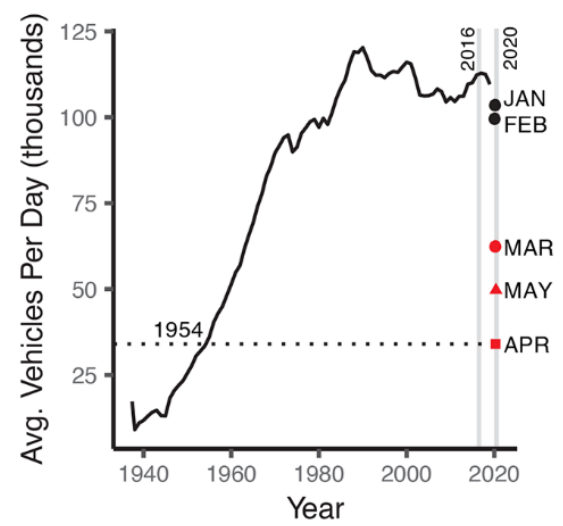

B

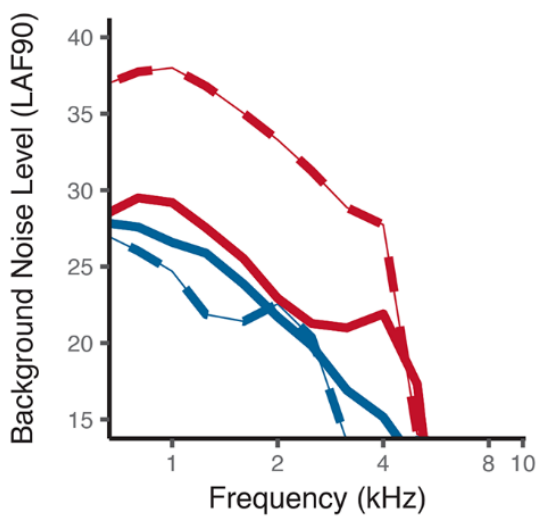

D

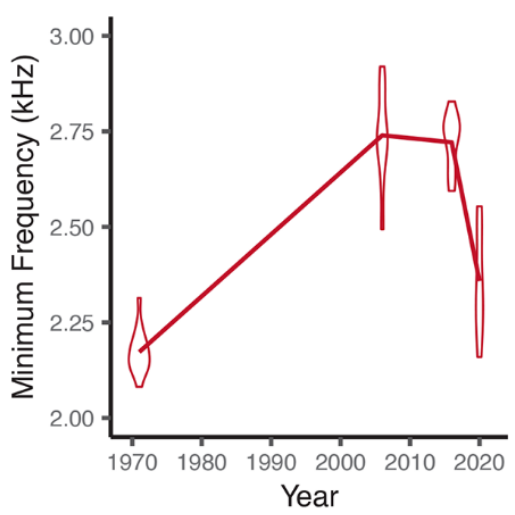

Fig. 2. Background noise levels. (A) Background noise levels recorded in urban (red) and rural (blue) areas with regression lines representing modelpredicted changes in background noise levels before (2016) versus during (2020) the COVID-19 shutdown. (B) Power spectrums of background noise levels recorded before (dashed lines) versus during the shutdown (solid lines). Urban soundscapes during the shutdown converge on the spectral profile of rural soundscapes (solid lines closer together than dashed lines). (C) Toll data shows traffic flow on the Golden Gate Bridge in San Francisco between 1937 and 2020. Vertical gray bars mark the years before (2016) and during (2020) the shutdown when background noise levels were recorded in order to illustrate the concurrent decline in the average number of vehicles crossing the bridge per day in March-May 2020 (red dots), returning to levels not seen since the 1950s (indicated by dashed line). (D) Violin plots of trill minimum frequency for the Berkeley song dialect recorded in Richmond in 1971, 2006, 2016 and 2020. Line connects the mean for each time point. 


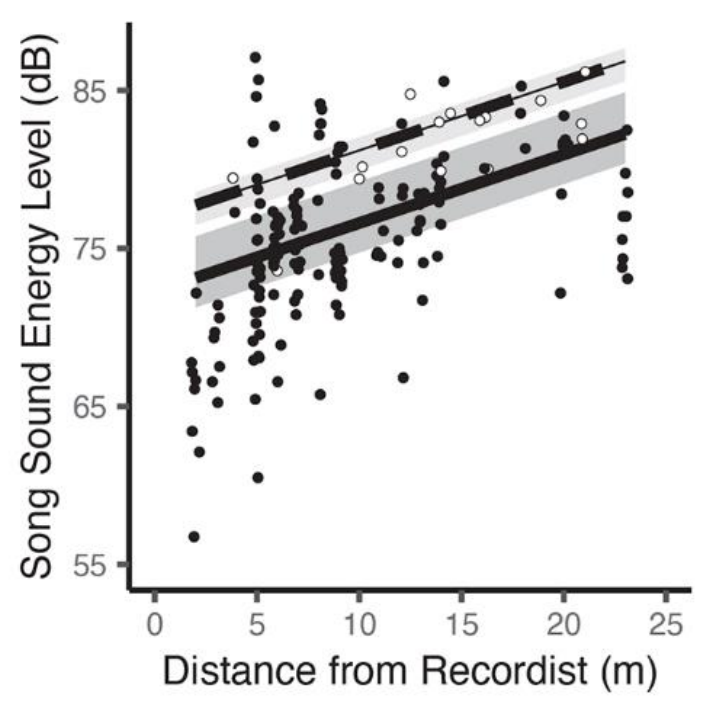

Fig. 3. Scatterplot of song amplitude versus distance between the recordist and bird. Regression lines represent modelpredicted changes in song energy levels for songs recorded before (open circles, dashed line) versus during (closed circles, solid line) the COVID-19 shutdown from a slice of immediate ambient noise conditions (43-53 dB) with the full range of noise levels illustrated in fig. S3. Gray regions illustrate the middle $50 \%$ of the bird random effect (i.e., individual variation). 

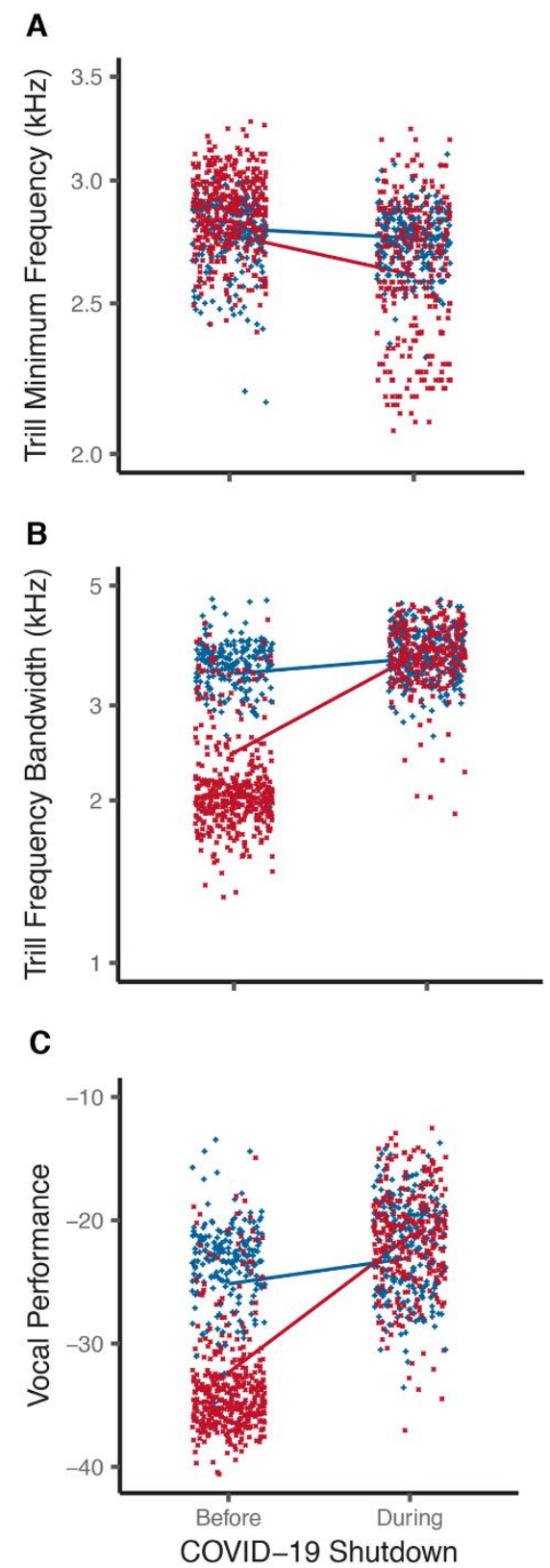

Fig. 4. Scatterplots of raw data. Shown are data recorded in urban (red) and rural (blue) areas with regression lines representing model-predicted changes in traits before versus during the recent statewide COVID-19 shutdown for trill (A) minimum frequency, (B) frequency bandwidth, and (C) vocal performance. Frequency measures were plotted on a log scale because pitch perception functions on a log scale. 